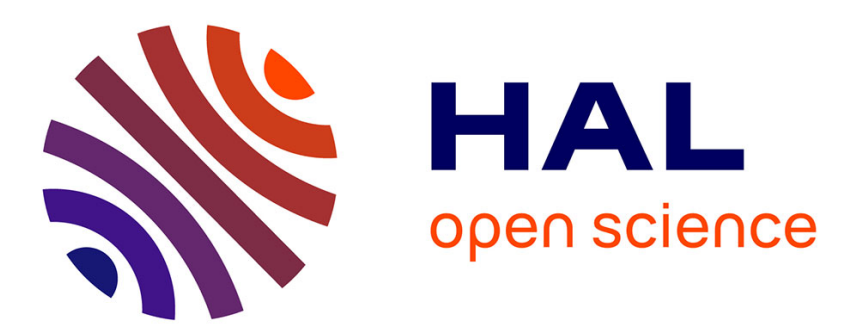

\title{
High genetic diversity of the symbiotic dinoflagellates in the coral Pocillopora meandrina from the South Pacific
}

Hélène Magalon, Emmanuelle Baudry, Aurélie Husté, Mehdi Adjeroud, Michel Veuille

\section{- To cite this version:}

Hélène Magalon, Emmanuelle Baudry, Aurélie Husté, Mehdi Adjeroud, Michel Veuille. High genetic diversity of the symbiotic dinoflagellates in the coral Pocillopora meandrina from the South Pacific. Marine Biology, 2006, 148 (148), pp.913-22. hal-00941726

\author{
HAL Id: hal-00941726 \\ https://hal.science/hal-00941726
}

Submitted on 6 May 2016

HAL is a multi-disciplinary open access archive for the deposit and dissemination of scientific research documents, whether they are published or not. The documents may come from teaching and research institutions in France or abroad, or from public or private research centers.
L'archive ouverte pluridisciplinaire HAL, est destinée au dépôt et à la diffusion de documents scientifiques de niveau recherche, publiés ou non, émanant des établissements d'enseignement et de recherche français ou étrangers, des laboratoires publics ou privés. 
H. Magalon • E. Baudry $\cdot$ A. Husté

M. Adjeroud · M. Veuille

\section{High genetic diversity of the symbiotic dinoflagellates in the coral Pocillopora meandrina from the South Pacific}

\begin{abstract}
Symbioses between dinoflagellates in the genus Symbiodinium (commonly referred to as zooxanthellae) and scleractinian corals are an essential feature for the maintenance of coral reefs. The fine-scale diversity and population structure of the zooxanthellae inhabiting the coral Pocillopora meandrina, a major reef building species in Polynesia, was examined. We used two polymorphic microsatellites to study seven populations from the South Pacific, whose host structuring has been previously investigated. The symbionts of $P$. meandrina showed high levels of diversity, with more than one zooxanthella genotype being identified in most of the host individuals. Genetic differentiation between sym-
\end{abstract}

H. Magalon $(\square) \cdot$ M. Veuille

EPHE, UMR CNRS 7625, Université Pierre et Marie Curie,

7 quai saint Bernard, 75005 Paris, France

E-mail: hmagalon@snv.jussieu.fr

Tel.: + 33-1-44272694

Fax: + 33-1-44273516

E. Baudry

UMR CNRS 8079, Laboratoire Ecologie,

Systématique et Evolution, Université Paris-Sud,

Bat 362, 91405 Orsay Cedex, France

A. Husté · H. Magalon · M. Veuille

Laboratoire Fonctionnement et Evolution des Systèmes

Ecologiques, Université Pierre et Marie Curie,

7 quai saint Bernard, 75005 Paris, France

M. Adjeroud

EPHE, UMR CNRS 8046

Laboratoire de Biologie Marine et Malacologie,

Université de Perpignan, 66860 Perpignan, France

M. Adjeroud

CRIOBE (Centre de Recherches Insulaires et Observatoire

de l'Environnement), BP 1013 Papetoai, Moorea,

French Polynesia

Present address: M. Veuille

Departement Systématique et Evolution, MNHN, 16 rue Buffon, 75005 Paris, France biont populations was detected at a large scale $(2,000 \mathrm{~km})$ between the Tonga and the Society Archipelagos. Within the Society Archipelago, the two most remote populations (Tahiti and Bora-Bora; $200 \mathrm{~km}$ apart) were only weakly differentiated from each other. Statistical tests demonstrated that the symbiont genetic structure was not correlated with that of its host, suggesting that dispersal of the symbionts, whether they are transported within a host larva or free in the water, depends mainly on distance and water currents. In addition, the data suggests that hosts may acquire new symbionts after maternal transmission, possibly following a disturbance event. Lastly, the weak differentiation between symbiont populations of $P$. verrucosa and $P$. meandrina, both from Moorea, indicated that there was some host-symbiont fine-scale specificity detectable at the genetic resolution offered by microsatellites.

\section{Introduction}

Coral reefs are characterized by animal-algal endosymbiosis, which plays a key role in a reef's productivity and growth. All reef-building corals, along with many other cnidarians, molluscs and protists, live in symbiosis with photosynthetic algae, commonly known as zooxanthellae (reviewed in Trench 1993). These symbiotic dinoflagellates provide the host with nutrients, thereby promoting animal growth and reproduction as well as enhancing calcification in scleractinian corals (Gattuso et al. 1999). In return, the host provides its symbionts with inorganic nutrients and habitat structure, protecting them against grazing and UV. Many authors have focused on this association when attempting to understand how corals will react when faced with stressful conditions conducive to bleaching, i.e., the loss of 
pigments of the zooxanthellae or the expulsion of the symbionts from the host (Glynn 1993; Brown 1997). A number of factors can trigger coral bleaching: e.g., extremes of temperature, high irradiance, darkness, heavy metals, and pathogenic micro-organisms (reviewed in Brown et al. 2000). But it is often due to the synergistic action of light (Banaszak and Trench 1995) and temperature (Perez et al. 2001) that damages the zooxanthella photosystem. The loss of zooxanthellae during bleaching can lead to widespread coral mortality and degradation of reef ecosystems. Thus, many researchers focus on this partner of the association and attempt to explore its diversity.

Zooxanthellae typically belong to the genus Symbiodinium and 11 species have now been identified by morphological, physiological and molecular criteria (reviewed in Baker 2003). Diversity of zooxanthellae from a wide range of hosts has been explored using molecular techniques and DNA sequence with different levels of resolution (reviewed in Baker 2003; Coffroth and Santos 2005). Zooxanthellae are typically classified as belonging to one of several different clades (reviewed in Baker 2003; Coffroth and Santos 2005). The ribosomal DNA internal transcribed spacer (ITS) is often used to identify zooxanthellae clades and to explore intra-cladal diversity (Hunter et al. 1997; Baillie et al. 2000; Brown et al. 2000; LaJeunesse and Trench 2000; LaJeunesse 2001; Pochon et al. 2001; Santos et al. 2001; van Oppen et al. 2001b; Brown et al. 2002; LaJeunesse 2002; Savage et al. 2002a). Indeed, sequence variation in this molecule has led to the definition of "sub-clades" (based on ITS1, for e.g., van Oppen et al. 2001b; Fabricius et al. 2004) or "types" (based on ITS2 DGGE profiles, LaJeunesse and Trench 2000; LaJeunesse 2001, 2002; LaJeunesse et al. 2003, 2004a, 2004b) within Symbiodinium. This algal diversity is probably a major reason for the spatial variability of coral bleaching events. Clades were first thought to correspond to ecological types with different photoacclimation abilities, but this idea is now controversial as differential sensitivity to thermal stress among various Symbiodinium seems to be distributed across all clades (Tchernov et al. 2004), as is sensitivity to irradiance (Savage et al. 2002b). DNA genotyping of zooxanthellae using ribosomal loci is therefore not a straightforward way to diagnose thermal and light sensitivities in these symbiotic associations. Until now, very few studies have explored zooxanthellae genetic diversity within the same sub-clade or the same type (Santos et al. 2003; Santos et al. 2004). These studies employed microsatellites and their flanking regions to investigate fine-scale diversity and population structure of Symbiodinium type B1/B184 in symbiosis with Caribbean gorgonians. Santos et al. (2003) documented significant population differentiation among Symbiodinium sp. clade B inhabiting the gorgonian Pseudopterogorgia elisabethae from different Bahamian reefs. Moreover, Santos et al. (2004) compared the genetic diversity of Symbiodinium belonging to the same lineage inhabiting different sympatric gorgonian hosts and demonstrated the existence of fine-scale specificity between Caribbean octocorals and their symbionts. Thus, microsatellites are useful tools in exploring the genetic complexity of Symbiodinium.

Two distinct modes of zooxanthellae acquisition exist in corals. Transmission can either be vertical, i.e., direct transmission from the mother colony to the eggs, or horizontal, i.e., acquisition from the environment by the host larva or juvenile. It is frequently thought that maternal transmission should result in a lower symbiont diversity than horizontal transmission, which allows each host generation to acquire new zooxanthellae. In the case of horizontal transmission, the initial uptake of zooxanthellae by juvenile corals during natural infection may be specific or non-specific, depending on the particular host (Coffroth et al. 2001; Weis et al. 2001; Schwarz et al. 2002; Little et al. 2004; Rodriguez-Lanetty et al. 2004). Thus, the association between the two partners may be considered flexible and characterized by changes in the zooxanthella types over time with the changing physiological needs of the host, in response to life history stage requirements or ambient environmental conditions (Little et al. 2004). For these reasons, even though host-symbiont specificity can occur, a lack of correlation between host and symbiont genotypes is expected in horizontal transmission, whereas coevolution between host and symbiont might be a predicted outcome in vertical transmission.

In this study, we investigated the fine-scale genetic diversity and genetic structuring of the Symbiodinium inhabiting seven populations of the coral Pocillopora meandrina from French Polynesia and Tonga, using two polymorphic microsatellites (Magalon et al. 2004). The symbionts of $P$. meandrina from these two remote regions belong to the same sub-clade $\mathrm{C} 1$ defined by van Oppen et al. (2001b) and are branched with the ITS2 type C1d defined by LaJeunesse (2001) (Magalon et al. unpublished data). Currently, microsatellites have been utilized in only a few studies to explore zooxanthellae genetic diversity and population structure within the same type (Santos et al. 2003; Santos et al. 2004). We also compared symbiont genetic structure to that of its hosts, which has been previously studied (Magalon et al. 2005). This comparison is interesting since few studies have focused on the diversity of both partners simultaneously at the population level.

\section{Materials and methods}

\section{Sample collections}

The sampling scheme employed in this study has been previously described (Magalon et al. 2005). Briefly, $P$. meandrina was sampled between March 2001 and December 2003 from seven sites on four Pacific islands, with three belonging to the Society Archipelago (Tahiti, Moorea, Bora-Bora) and one belonging to Tongatapu, an island in the Tonga Archipelago (Fig. 1). From the 
Fig. 1 Localities from which $P$. meandrina and $P$. verrucosa were collected (population names are in bold)

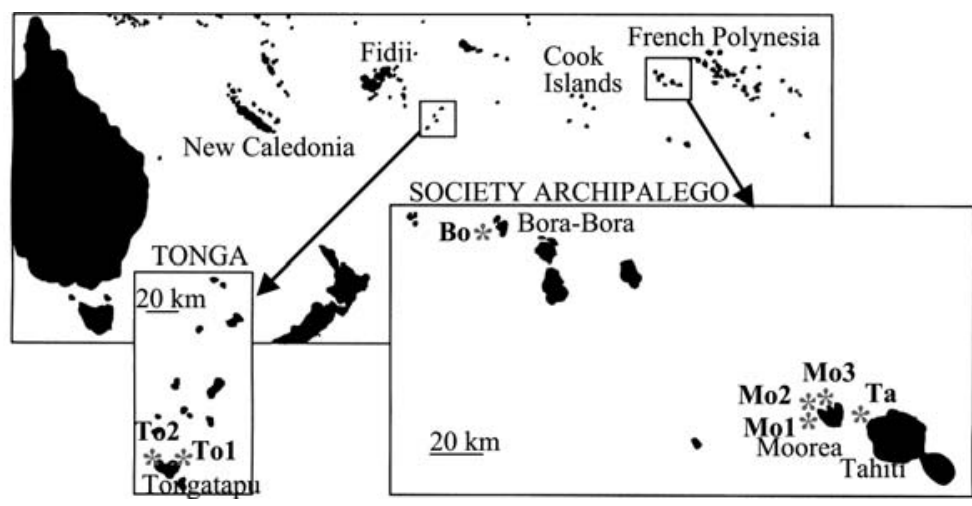

easternmost island (Tahiti), the distances to the other islands are $20 \mathrm{~km}$ (to Moorea), $200 \mathrm{~km}$ (to Bora-Bora) and $2,000 \mathrm{~km}$ (to Tonga). The Tahiti population (hereafter referred to as $\mathrm{Ta}$ ) and the Bora-Bora population (Bo) were sampled in December 2003. The three populations from Moorea, situated at 5-km intervals, were sampled in March 2001 from Haapiti (Mo1), Tiahura (Mo2), and Vaipahu (Mo3). All samples from French Polynesia were collected from the outer reef slope. Two populations from Tonga were sampled in August 2002: one from the lagoon (To1), and the other from the outer reef slope (To2). In order to compare the zooxanthellae populations of a different host species, an eighth population, composed of $P$. verrucosa individuals, was also sampled at the site Mo3. This population is named Mo3-Pv.

Both $P$. meandrina and $P$. verrucosa are branching corals. Branch tips of colonies were collected along a linear transect at $13 \mathrm{~m}$ depth at all sites, except To1 (2$6 \mathrm{~m}$ depth). In order to avoid collecting clones propagated by asexual reproduction through the fragmentation of branch tips, colonies were collected every $5 \mathrm{~m}$ along the transect. All individuals were identified as $P$. meandrina or $P$. verrucosa using morphoanatomical criteria. Samples were preserved in $70 \%$ ethanol until use. Total DNA (i.e., zooxanthella DNA and coral DNA) was extracted using the DNEasy Tissue kit (Qiagen), following the manufacturer's instructions, from $300 \mathrm{mg}$ of coral powder obtained by grinding the branch tips.

\section{Microsatellite typing}

We used two zooxanthella-specific microsatellite loci (PV1 and PV4) that have been developed from $P$. verrucosa symbionts and are also polymorphic for $P$. meandrina symbionts (Magalon et al. 2004). Amplification and genotyping assays were performed using standard conditions, as previously described (Magalon et al. 2004). We detected a frequent null allele at locus PV1, leading us to design a novel pair of primers that were external to the former primers (PV1bis-for: 5'-GGA CCA AGC TGA ATA ATT TG-3'-FAM and PV1bisrev: 5'-ACC AAG GTA CTG TAG TTG TTA TG-3').
The annealing temperature, Tm, and PCR conditions were identical to those for the PV1 locus reported previously (AY 397776, detailed in Magalon et al. 2004).

\section{Data analysis}

Since several alleles were often detected in one coral host individual and as Symbiodinium are haploid (Santos and Coffroth 2003), each allele detected in a coral individual was treated as a single genotype representing a unique zooxanthella type. Descriptive statistics are presented in Table 1. As we faced with the difficulty of reconstructing specific two-locus genotypes, we conducted two types of statistical analyses on our non-classical data set. First, for each locus and each population, allele frequencies were calculated by considering the total number of detected peaks as the total number of zooxanthellae types present in a coral population. This representation of the zooxanthella community is biased because the more frequent alleles, as well as the number of genotypes, are underestimated. However, it has the advantage of giving a qualitative picture of the community. We then calculated for each population and each locus the estimated number $(n)$ of zooxanthellae types, the number of host individuals presenting 1-allele, 2-alleles, 3-alleles and 4alleles genotypes and the gene diversity $H$ (Nei 1978) using Arlequin version 2.00 (Schneider et al. 2000).

Second, to combine the information of the two loci simultaneously, we coded the presence or absence of an allele in a coral individual as would be done in restriction fragment length polymorphism analyses. To estimate the independence between all zooxanthellae types, we conducted linkage disequilibrium tests between all pairs of alleles at both loci for each population using Arlequin version 2.00 (Schneider et al. 2000). Bonferroni corrections were used to correct for multiple testing (Rice 1989). $F_{S T}$ statistics (Weir and Cockerham 1984) from all pairwise population comparisons were calculated using Arlequin version 2.00 (Schneider et al. 2000). This statistic assumes that alleles are evolving under an Infinite Allele Model (IAM) and estimates the probabilities of identity between alleles. Similar measures have also been calculated for the host populations data set previously 
Table 1 Allele frequencies at loci PV1bis and PV4 for symbionts of P. meandrina populations

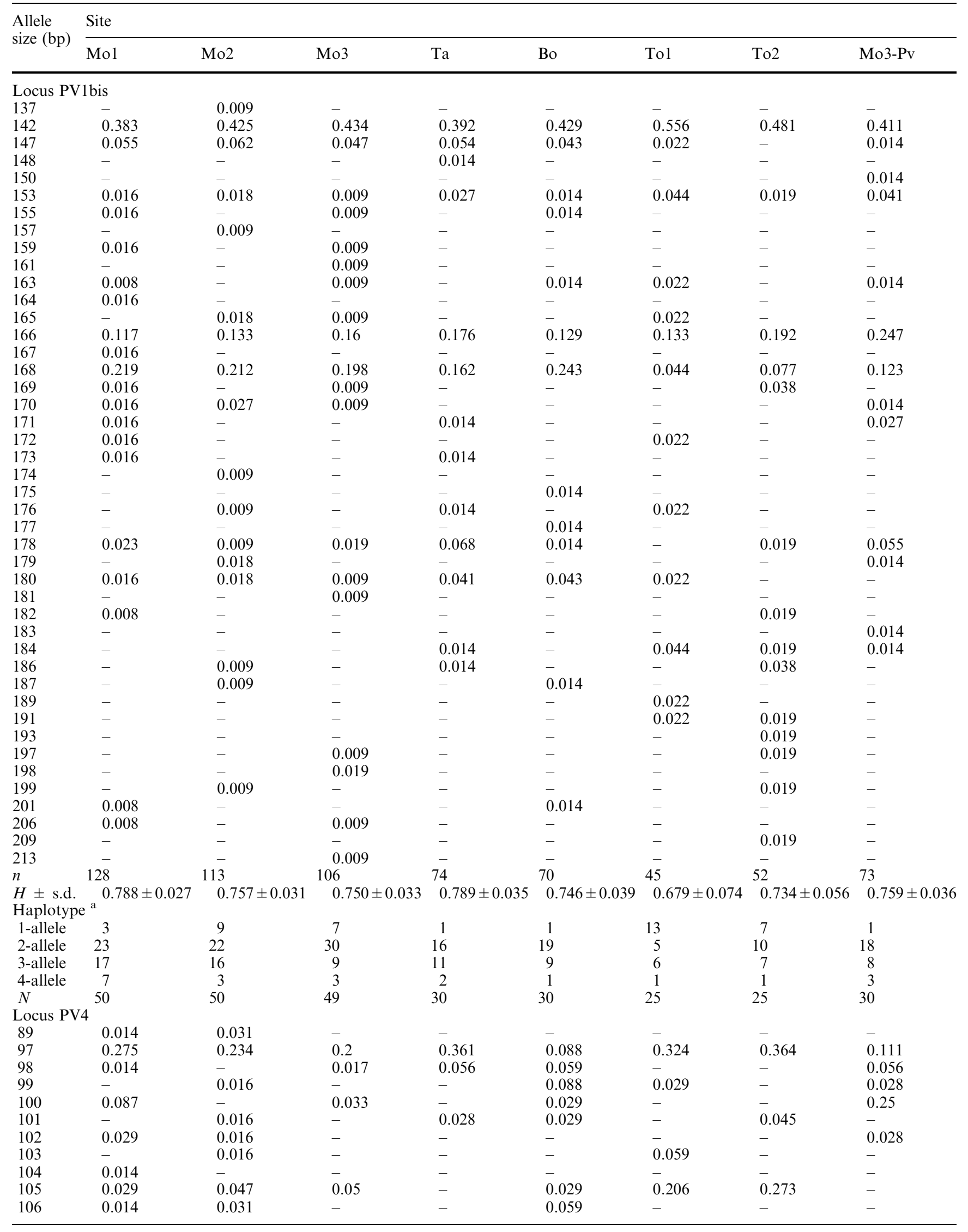


Table 1 (Contd.)

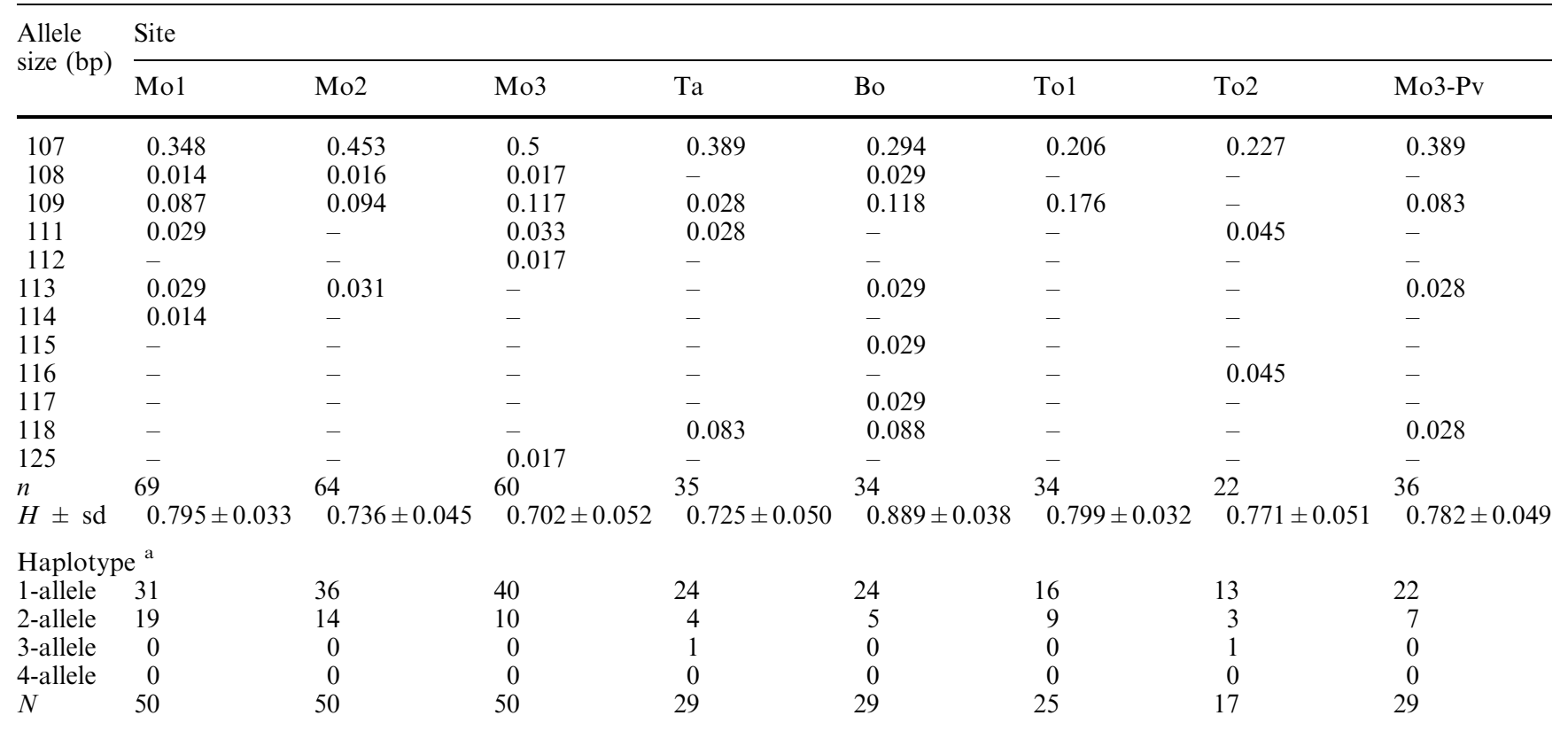

$n$ is the total number of zooxanthellae types genotyped for each population, $H$ is the gene diversity; $N$ is the total number of haplotype (i.e., the total of $P$. meandrina individuals studied for each population). The occurrence of each zooxanthellae type is obtained by multiplying $n$ and the frequency ${ }^{\mathrm{a}}$ Number of colonies with $1,2,3$ or 4 zooxanthellae types

studied (Magalon et al. 2005). The population Mo3-Pv was examined with the same coral-specific microsatellites as in Magalon et al. (2005) and was integrated into the seven $P$. meandrina populations. Additionally, for both host and symbiont populations, Slatkin's linear genetic distances $\left(D=F_{S T} /\left(1-F_{S T}\right)\right)$ (Slatkin 1993) were calculated between all pairs of populations over all loci using Arlequin version 2.00 (Schneider et al. 2000), and the distances were graphically represented as a dendrogram using the neighbor-joining algorithm in MEGA version 2.1 (Kumar et al. 2001).

The associations between genetic structure of the host populations, the genetic structure of symbiont populations and space were investigated with Mantel tests (Legendre and Fortin 1989). Mantel analyses test correlations between two matrices (simple Mantel test) or between two matrices while controlling for the effect of a third matrix (partial Mantel test) (Smouse et al. 1986; Legendre and Fortin 1989). In order to perform these analyses, two matrices (one for the host population and one for the symbiont population) of genetic distances (estimated by $F_{S T}$ ) were built. A matrix of Euclidian distances between pairs of populations (estimated by the logarithm of distance in kilometers) was also constructed. The Mantel's and partial Mantel's $r$-value was tested for significance by 1,000 permutations using Arlequin version 2.00 (Schneider et al. 2000).

\section{Results}

Population variation

Allele data per population and per locus are given in Table 1. We identified a total of 44 and 23 alleles from loci PV1bis and PV4, respectively. Allele sizes ranged between 137 and 213 bp for locus PV1bis and between 89 and 125 bp for locus PV4. Among these alleles, three and two alleles were most frequent at loci PV1bis and PV4, respectively. At locus PV1bis, 97.6, 35.6 and 40.5

Table 2 Pairwise multilocus estimates of $F_{S T}$ for zooxanthella populations (below diagonal) and for coral populations (above diagonal)

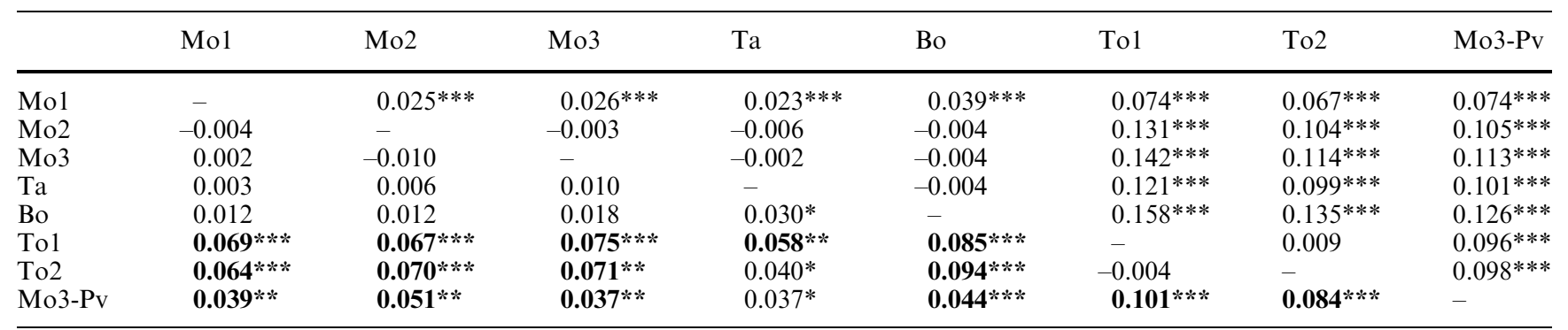

Significance at the * $P \leq 0.05, * * P \leq 0.01, * * * P \leq 0.001$ level. Significant $F_{S T}$ values after a sequential Bonferroni correction are in bold for zooxanthellae populations 
Fig. 2 Neighbor-Joining tree of $\mathbf{a}$ all host populations and $\mathbf{b}$ all symbiont populations using Slatkin $F_{S T}$ distances
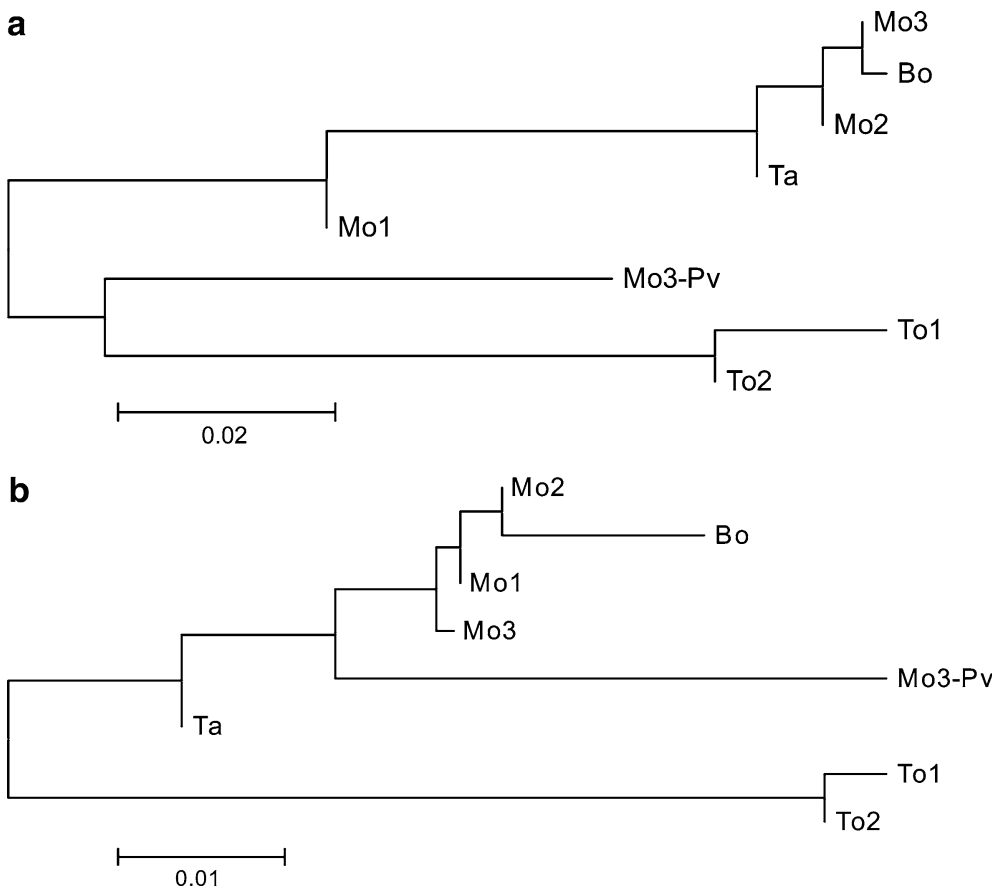

$\%$ of the 289 colonies harbored genotypes with alleles 142, 166 and 168, respectively, while at locus PV4, 32 and $50.6 \%$ of all colonies harbored genotypes with alleles 97 and 107, respectively. Estimates of gene diversity $(H)$ within populations ranged from 0.679 (for population To1) to 0.789 (for Ta) for locus PV1bis and from 0.702 (for Mo3) to 0.889 (for Bo) for locus PV4. At locus PV1bis, 14.7, 49.4, 28.7 and $7.2 \%$ of all coral individuals exhibited one, two, three and four alleles, respectively, whereas at locus PV4, all coral individuals exhibited either one $(74.6 \%)$ or two alleles $(25.4 \%)$. Among the 2,451 linkage disequilibrium tests between all polymorphic alleles for each population, 162 were significant at the $5 \%$ level and only $72(2.9 \%)$ remained significant after the Bonferroni correction. Therefore no particular association was detected between the different zooxanthellae types.

\section{Population differentiation}

With one exception, differentiations between populations from the same archipelago were not significant, whereas all differentiations between one population from the Society Archipelago and one population from Tonga were significant. Significant pairwise $F_{S T}$ between populations (Table 2) ranged from 0.030 (Ta vs. Bo) to 0.101 (To1 vs. Mo3-Pv). However, since our analyses were performed using only two microsatellites markers, our results should be interpreted with caution. The Tonga populations were differentiated from the Society populations while within the Society archipelago, population Ta from Tahiti was slightly, but significantly, differentiated from population Bo at Bora-Bora (these populations are located on the two most distant islands of the archipelago). Interestingly, the symbionts of the $P$. verrucosa population Mo3-Pv from Moorea were significantly different from all the symbiont populations of $P$. meandrina (mean significant $F_{S T}=0.056$ ). As for the host populations, the population Mo3-Pv of $P$. verrucosa is also significantly different from all other host populations (mean $F_{S T}=0.102$, Magalon et al. 2005). The Neighbor-Joining trees using Slatkin-linearized $F_{S T}$ distances illustrate these observations (Fig. 2a and b).

Regarding the host, the population of $P$. verrucosa from Moorea Mo3-Pv was significantly differentiated from the $P$. meandrina populations at the same site. However, the $P$. meandrina populations from Tonga and from the Society Islands are as differentiated from each other (mean $F_{S T}=0.114$ ) as $\mathrm{Mo} 3-\mathrm{Pv}$ is to the $P$.

Table 3 Mantel (above diagonal) and partial Mantel (below diagonal) correlations between matrices of $P$. meandrina population pairwise $F_{S T}, P$. meandrina symbiont population pairwise $F_{S T}$ and geographic distance (transformed by $\log$ )

\begin{tabular}{|c|c|c|c|}
\hline & $\begin{array}{l}P . \text { meandrina population } \\
\text { pairwise } F_{S T}\end{array}$ & $\begin{array}{l}P . \text { meandrina symbiont } \\
\text { population pairwise } F_{S T}\end{array}$ & Geographic distance \\
\hline P. meandrina population pairwise $F_{S T}$ & - & $0.896^{* *}$ & $0.808^{*}$ \\
\hline Geographic distance & 0.075 & $0.732 * *$ & - \\
\hline
\end{tabular}

The $P$. verrucosa population Mo3-Pv has been removed from this analysis. Significant at $* P \leq 0.05, * * P \leq 0.01, * * * P \leq 0.001$ level after a sequential Bonferroni correction. Data in bold remained significant when Mantel tests were restricted to French Polynesia populations 
meandrina populations (mean $F_{S T}=0.102$ ). This kind of pattern is commonly observed between closely related coral species and is usually explained by reticulate evolution, i.e., the frequent occurrence of hybridization and introgression (Van Oppen et al. 2000; van Oppen et al. 2001a; Vollmer and Palumbi 2002; Fukami et al. 2004; Van Oppen et al. 2004). Alternatively, we could imagine that the populations of Tonga do not belong to $P$. meandrina but to a third species.

\section{Comparisons of symbiont and host population} structures

Mantel tests permitted us to investigate any link between host population structure and symbiont population structure by testing whether differentiation between symbiont populations were related to the differentiation between the corresponding host populations or simply to their geographic distance. At the scale of the South Pacific, significant positive Mantel correlations were found between the $P$. meandrina population $F_{S T}$ matrix and the distance matrix $(r=0.808, P \leq 0.05)$, between the $P$. meandrina symbiont $F_{S T}$ matrix and the distance matrix $(r=0.919, P \leq 0.001)$, and between the host $F_{S T}$ and symbiont $F_{S T}$ matrices $(r=0.896, P \leq 0.01$; see Table 3). The results of the partial Mantel test showed a significant relationship between symbiont population structure and host population structure when the effect of distance separating populations was controlled for $(r=0.658, P \leq 0.05)$. Similarly, a significant relationship between symbiont population structure and distance separating populations was observed when the effect of host population structure was controlled for $(r=0.732$, $P \leq 0.01$; see Table 3 ). Thus, variation in symbiont population structure among sites appeared partly related to variation in host population structure, but also to the geographic location of sites.

At the scale of the Society Archipelago, significant positive correlations were found between the $P$. meandrina symbiont $F_{S T}$ and distance matrices $(r=0.869$, $P<0.05)$ whether or not the effect of host population structure was controlled for $(r=0.874, P<0.05)$. On the other hand, correlations between the symbiont $F_{S T}$ and its host population $F_{S T}$ matrices were not significant, whether or not the effect of distance separating populations was controlled for (all $P>0.05$ ). The lack of correlation between the symbiont and host matrices demonstrates that host and symbiont population structures are independent at this scale $(200 \mathrm{~km})$.

\section{Discussion}

Structure of the zooxanthellae populations inhabiting P. meandrina

At the scale of the Society Archipelago, none of the symbiont populations examined were differentiated from each other, except the two most distant populations Ta and Bo, which are from Tahiti and Bora-Bora, respectively. Separated by $200 \mathrm{~km}$, they exhibited weak, but significant, differentiation. At the scale of the South Pacific, symbiont populations from Tonga and from the Society Archipelago were significantly differentiated from each other. However, the dispersal of zooxanthellae seems quite widespread since the same common alleles were found in the two archipelagos. To determine whether these shared alleles were identical by descent or are due to size homoplasy (Viard et al. 1998; Adams et al. 2004), we sequenced one shared allele per locus. We found identical sequences, suggesting that the shared alleles are truly identical by descent. Zooxanthellae may disperse by at least two different modes. Cells may be released into the water column by the host (Maruyama and Heslinga 1997; Bhagooli and Hidaka 2004) and then passively transported by currents and tides. In this case, free-living symbionts are strongly subjected to environmental constraints, such as limited access to nutrients, and their lifespan may be consequently short. Alternatively, they may reside in hospite in coral larvae, with their dispersal dependent on the larvae's dispersal ability as well as on oceanic currents. Mantel tests restricted to the French Polynesia populations showed that, at this scale, the genetic structure of the symbiont populations depends on geographic distances while being independent of the host population genetic structure. These results suggest that zooxanthella population structure is primarily governed by oceanic currents and the distance separating populations. The global pattern of isolation by distance can be explained by the oceanic currents that bath the islands of Polynesia (Rougerie and Wauthy 1986) and the islands of the South Pacific (the Pacific South Equatorial Current flowing from east to west). These currents likely promote zooxanthellate larvae or free zooxanthellae dispersal between neighboring populations on successive reefs and islands. Distancedependent dispersal has also been documented for coral populations in French Polynesia (Magalon et al. 2005; when the population Mol from Moorea is excluded) and for Symbiodinium clade B zooxanthellae in the Bahamas (Santos et al. 2003).

\section{Zooxanthella acquisition}

Our study demonstrates that a host individual can harbor several zooxanthellae types (here, from one to four) simultaneously, as identified genetically by microsatellite markers. We observed a higher number of alleles at locus PV1bis than at PV4, which could be due to a difference of mutation rate between the two microsatellite loci. Indeed, mutation process is heterogeneous with respect to loci, repeat types and organisms (reviewed in Ellegren 2004). Given the presence of more than one zooxanthella type per host and as we are not able to determine whether a peak is the product of one or more copies of an allele, it was not possible to elaborate a 
posteriori all the symbiont genotypes present in a single host individual. This is a frequent issue in studies of polyploid organisms (see e.g., Korbecka et al. 2003). The number of genetically different symbionts per $P$. meandrina colony is quite different compared to other cnidarian hosts. Goulet and Coffroth (2003) found only one unique zooxanthella genotype in each of the studied Plexaura kuna colonies using DNA fingerprints. Santos et al. (2003) found only a single allele per microsatellite locus for the majority of the individuals of Pseudopterogorgia elisabethae and $P$. kuna examined, allowing them to reconstruct haploid genotypes.

Thus, the association of $P$. meandrina with its symbionts seems more flexible (i.e., association with several different types of zooxanthellae simultaneously) than that of the gorgonians. Moreover, there was no correlation between the genetic distances of the symbionts and genetic distances of their hosts, and no particular association between the different zooxanthellae types being identified by the linkage disequilibrium tests. This suggests that the acquisition of zooxanthellae from the environment by $P$. meandrina might occur at the larval stage or during post-larval settlement. However, many studies have reported that $P$. damicornis, $P$. verrucosa and $P$. eydouxi from different regions [Japan (Hirose et al. 2000; Harii et al. 2002), Eastern Pacific (Glynn et al. 1991), Maldives (Sier and Olive 1994) and South Africa (Kruger and Schleyer 1998)] contained zooxanthellae in their oocytes, indicating maternal transmission. Even if $P$. meandrina is not mentioned specifically in these studies, it is probable that $P$. meandrina also harbors zooxanthellae in its mature oocytes prior to spawning since this species is closely related to the ones cited above.

Maternal transmission is usually thought to induce low symbiont diversity and correlations between the genetic structure of hosts and their symbionts. Our results therefore seem to contradict the likely maternal transmission of symbionts in $P$. meandrina. Such a discrepancy has also been observed by Van Oppen (2004) for acroporid corals of the Montipora genus. One possible explanation is that corals that transmit their symbionts maternally are also capable of acquiring symbionts from the environment by horizontal transmission, either during early development, or as adults, such as following a disturbance. This last case could be a frequent event in French Polynesian populations, as they are often subjected to bleaching events (Hoegh-Guldberg and Salvat 1995; Mumby et al. 2001). The acquisitions of symbionts could potentially be non-specific, since Little et al. (2004) showed that the first acquisition of zooxanthellae are not specific, followed by selection of the types best adapted to their habitat conditions. The acquisition of exogenous symbionts (Lewis and Coffroth 2004 ) or the presence of several symbionts in a single $P$. meandrina provides a mechanism for response to changes in the environment. When colonies face stressful conditions, they may cope with disturbances by regulating the relative abundances of each zooxanthellae type.

\section{Host specificity}

It is interesting to note that the symbiont populations from the two populations at Tonga, To1 and To2 (collected in the lagoon and on the outer slope, respectively), are not differentiated even if they are located in two environments with contrasting irradiance and temperature regimes. Thus, at this scale, we have not detected an "ecological type", similar to what has been reported for the Symbiodinium B1/B184 genotypes of P. elisabethae (Santos et al. 2003). However, we cannot generalize beyond this, since only two populations have been included in this comparison.

Furthermore, we found that the $P$. verrucosa symbiont population was significantly differentiated from all $P$. meandrina symbiont populations (mean $F_{S T}=0.056$ ), even that of Mo3, which originated from the same site at Moorea (significant $F_{S T}=0.037$ ). Therefore, we can conclude that there is some evidence for host-symbiont fine-scale specificity in the examined systems. However, the differentiation between the two symbiont populations is relatively low, which could be due to a low selectivity of $P$. meandrina and $P$. verrucosa. They would therefore partly harbor the same symbionts because they are very closely related and they inhabit the same geographic location (LaJeunesse et al. 2004a, 2004b).

In conclusion, we have found that (1) the symbionts of $P$. meandrina are genetically very diverse, (2) their structure is not congruent with that of their host, and (3) there is a weak host-symbiont specificity within both $P$. meandrina and $P$. verrucosa at the genetic resolution level of microsatellites. Furthermore, our data suggest that (4) algal dispersal is mainly governed by oceanic currents and (5) secondary acquisition of symbionts probably occurs in these scleractinian corals.

Acknowledgements We thank Scott R. Santos for helpful advice, valuable comments and corrections, and Todd C. LaJeunesse for his help in zooxanthellae identification and relevant comments. We also thank the three anonymous reviewers for their comments that improved the manuscript. We thank the French Ministère de l'Outremer. This research was supported by a grant from the EPHE PPF network to Michel Veuille, by a grant from the TotalFinaElf Foundation to Mehdi Adjeroud, and by a Docteur-Ingénieur fellowship from the CNRS to Hélène Magalon.

\section{References}

Adams RI, Brown KM, Hamilton MB (2004) The impact of microsatellite electromorph size homoplasy on multilocus population estimates in a tropical tree (Corythopora alta) and an anadromous fish (Morone saxatilis). Mol Ecol 13:2579-2588

Baillie BK, Belda-Baillie CA, Maruyama T, . (2000) Conspecificity and indo-pacific distribution of Symbiodinium genotypes (Dinophycea) from giant clams. J Phycol 36:1153-1161

Baker A (2003) Flexibility and specificity in coral-algal symbiosis: Diversity, ecology and biogeography of Symbiodinium. Annu Rev Ecol Evol Syst 34:661-689

Banaszak AT, Trench RK (1995) Effects of ultraviolet (UV) radiation on marine microalgal-invertebrate symbioses.I. Response of the algal symbionts in culture and in hospite. J Exp Mar Biol Ecol 194:213-232 
Bhagooli R, Hidaka M (2004) Release of zooxanthellae with intact phtosynthetic activity by the coral Galaxea fascicularis in response to high temperature stress. Mar Biol 145:329337

Brown BE (1997) Coral bleaching: causes and consequences. Coral Reefs 16(Suppl):S129-S138

Brown BE, Dunne RP, Goodson MS, Douglas AE (2000) Bleaching patterns in reef corals. Nature 404:142-143

Brown BE, Dunne RP, Goodson MS, Douglas AE (2002) Experience shapes the susceptibility of a reef coral to bleaching. Coral Reefs 21:119-126

Coffroth MA, Santos SR (2005) Genetic diversity of symbiotic dinoflagellates in the genus Symbiodinium. Protist 156(1):19-34

Coffroth MA, Santos SR, Goulet TL (2001) Early ontogenetic expression of specificity in a cnidarian-algal symbiosis. Mar Ecol Prog Ser 222:85-96

Ellegren H (2004) Microsatellites: simple sequences with complex evolution. Genetics 5: 435-445

Fabricius KE, Mieog JC, Colin PL, Idip D, van Oppen MJ (2004) Identity and diversity of coral endosymbionts (zooxanthellae) from three Palauan reefs with contrasting bleaching, temperature and shading histories. Mol Ecol 13:2445-2458

Fukami H, Budd AF, Levitan JJ, Kernasach R, Knowlton N (2004) Geographic differences in species boundaries among members of the Montastraea annularis complex based on molecular and morphological species. Evolution 58:324-337

Gattuso JP, Allemand D, Frankignoulle M (1999) Photosynthesis and calcification at cellular, organismal and community levels in coral reefs: a review on interactions and control by carbonate chemistry. Am Zool 39:160-183

Glynn PW (1993) Coral reef bleaching: ecological perspectives. Coral Reefs 12:1-17

Glynn PW, Gassman NJ, Eakin CM, Cortes J, Smith DB, Guzman HM (1991) Reef coral reproduction in the eastern Pacific: Costa Rica, Panama and Galapagos Islands (Ecuador).I Pocilloporidae. Mar Biol 109:355-368

Goulet TL, Coffroth MA (2003) Genetic composition of zooxanthellae between and within colonies of the octocoral Plexaura kuna, based on small subunit rDNA and multilocus DNA fingerprinting. Mar Biol 142:233-239

Harii S, Kayanne H, Takigawa H, Hayashibara T, Yamamoto M (2002) Larval survivorship, competency periods and settlement of two brooding corals, Heliopora coerulea and Pocillopora damicornis. Mar Biol 141:39-46

Hirose M, Kinzie III RA, Hidaka M (2000) Early development of zooxanthella-containing eggs of the corals Pocillopora verrucosa and P.eydouxi with special reference to the distribution of zooxanthellae. Biol Bull 199:68-75

Hoegh-Guldberg O, Salvat B (1995) Periodic mass-bleaching and elevated sea temperatures: bleaching of outer reef slope communities in Moorea, French Polynesia. Mar Ecol Prog Ser 121:181-190

Hunter CL, Morden CW, Smith CM (1997) The utility of ITS sequences in assessing relationships among zooxanthellae and corals. Proc 8th Int Coral Reef Sym 2:1599-1602

Korbecka G, Vrieling K, Squirrell J, Hale ML, Wolff K (2003) Characterization of six microsatellite loci in Echium vulgare (Boraginaceae). Mol Ecol Notes 3:274-276

Kruger A, Schleyer MH (1998) Sexual reproduction in the coral Pocillopora verrucosa (Cnidaria: Scleractinia) in KwaZuluNatal, South Africa. Mar Biol 132:703-710

Kumar S, Tamura K, Jakobsen IB, Nei M (2001) MEGA2: Molecular Evolutionary Genetics Analysis software. Bioinfomatics 12:1244-1245

LaJeunesse TC (2001) Investigating the biodiversity, ecology, and phylogeny of endosymbiotic dinoflagellates in the genus Symbiodinium using the ITS region: In search of a "species" level marker. J Phycol 37:866-880

LaJeunesse TC (2002) Diversity and community structure of symbiotic dinoflagellates from Carribean coral reefs. Mar Biol $141: 387-400$
LaJeunesse TC, Bhagooli R, Hidaka M, deVantier L, Done T, Schmidt GW, Fitt WK, Hoegh GO (2004a) Closely related Symbiodinium spp. differ in relative dominance in coral reef host communities across environmental, latitudinal and biogeographic gradients. Mar Ecol Prog Ser 284:147-161

LaJeunesse TC, Loh W, van Woesik R, Hoegh GO, Schmidt GW, Fitt WK (2003) Low symbiont diversity in southern Great Barrier Reef corals, relative to those of the Carribean. Limnol Oceano 48:2046-2054

LaJeunesse TC, Thornhill DJ, Cox EF, Stanton FG, Fitt WK, Schmidt GW (2004b) High genetic diversity and host specificity observed among symbiotic dinoflagellates in reef coral communities from Hawaii. Coral reefs 23: 596-603

LaJeunesse TC, Trench RK (2000) Biogeography of two species of Symbiodinium (Freudenthal) inhabiting the intertidal sea anemone Anthopleura elegantissima (Brandt). Biol Bull 199:126-134

Legendre P, Fortin M-J (1989) Spatial pattern and ecological analysis. Vegetation 80:107-138

Lewis CL, Coffroth MA (2004) The acquisition of exogenous algal symbionts by an octocoral after bleaching. Science 304:1490 1492

Little AF, Van Oppen MJ, Willis BL (2004) Flexibility in algal endosymbioses shapes growth in reef corals. Science 304:1492-1494

Magalon H, Adjeroud M, Veuille M (2005) Patterns of genetic variation do not correlate with geographical distance in the reef building coral Pocillopora meandrina in the South Pacific. Mol Ecol 14:1861-1868

Magalon H, Samadi S, Richard M, Adjeroud M, Veuille M (2004) Development of coral and zooxanthella-specific microsatellites in three species of Pocillopora (Cnidaria, Scleractinia) from French Polynesia. Mol Ecol Notes 4:206-208

Maruyama T, Heslinga GA (1997) Fecal discharge of zooxanthellae in the giant clam Tridacna derasa, with reference to their in situ growth rate. Mar Biol 127:473-477

Mumby PJ, Chisholm JRM, Edwards AJ, Andrefouet S, Jaubert J (2001) Cloudy weather may have saved Society Island reef corals during the 1998 ENSO event. Mar Ecol Prog Ser 222:209-216

Nei M (1978) Estimation of average heterozygosity and genetic distance for small number of individuals. Genetics 89:583-590

Perez SF, Cook CB, Brooks WR (2001) The role of symbiotic dinoflagellates in the temperature-induced bleaching response of the subtropical sea anemone Aiptasia pallida. J Exp Mar Biol Ecol 256:1-14

Pochon X, Pawlowski J, Zaninetti L, Rowan R (2001) High genetic diversity and relative specificity among Symbiodinium-like endosymbiotic dinoflagellates in soritid foraminiferans. Mar Biol 139:1069-1078

Rice WR (1989) Analyzing tables of statistical tests. Evolution 43:223-225

Rodriguez-Lanetty M, Krupp DA, Weis VM (2004) Distinct ITS types of Symbiodinium in clade C correlate with cnidarian/ dinoflagellate specificity during onset of symbiosis. Mar Ecol Prog Ser 275:97-102

Rougerie F, Wauthy B (1986) L'Ocean qui nous entoure p73-78. Encyclopédie de la POlynésie vol I: les îles océaniques, Multipress. Papeete, Polynésie Française

Santos SR, Coffroth MA (2003) Molecular genetic evidence that dinoflagellates belonging to the genus Symbiodinium Freudenthal are haploid. Biol Bull 204:10-20

Santos SR, Gutiérrez-Rodriguez C, Lasker HR, Coffroth MA (2003) Symbiodinium sp. associations in the gorgonian Pseudopterogorgia elisabethae in the Bahamas high levels of genetic variability and population structure in symbiotic dinoflagellates. Mar Biol 143:111-120

Santos SR, Shearer TL, Hannes AR, Coffroth MA (2004) Finescale diversity and specificity in the most prevalent lineage of symbiotic dinoflagellates (Symbiodinium, Dinophyceae) of the Carribean. Mol Ecol 13:459-469 
Santos SR, Taylor DJ, Coffroth MA (2001) Genetic comparisons of freshly isolated versus cultured symbiotic dinoflagellates: Implications for extrapolating to the intact symbiosis. J Phycol 37:900-912

Savage AM, Goodson MS, Visram S, Trapido-Rosenthal H, Wiedenmann J, Douglas AE (2002a) Latitudinal diversity of symbiotic algae at the latitudinal margins of their distribution: dinoflagellates of the genus Symbiodinium in corals and sea anemones. Mar Ecol Prog Ser 244:17-26

Savage AM, Trapido-Rosenthal H, Douglas AE (2002b) On the functional significance of molecular variation in Symbiodinium, the symbiotic algae of Cnidaria: photosynthetic response to irradiance. Mar Ecol Prog Ser 244:27-37

Schneider S, Roessli D, Excoffier L (2000) Arlequin ver. 2.000: A software for population genetics data analysis. Genetics and Biometry Laboratory, University of Geneva, Switzerland

Schwarz JA, Weis VM, Potts DC (2002) Feeding behavior and acquisition of zooxanthellae by planula larvae of the sea anemone Anthopleura elegantissima. Mar Biol 140:471-478

Sier CJS, Olive PJW (1994) Reproduction and reproductive variability in the coral Pocillopora verrucosa from the Republic of Maldives. Mar Biol 118:713-722

Slatkin M (1993) Isolation by distance in equilibrium and nonequilibrium populations. Evolution 47:264-279

Smouse PE, Long JC, Sokal RR (1986) Multiple regression and correlation extensions of the Mantel test of matrix correspondence. Syst Zool 35:627-632

Tchernov D, Gorbunov MY, de Vargas C, Narayan Yadav S, Milligan AJ, Häggblom M, Falkowski PG (2004) Membrane lipids of symbiotic algae are diagnostic of sentivity to thermal bleaching in corals. PNAS 101(37):13531-13535
Trench RK (1993) Microalgal-invertebrate symbioses: a review. Endocyt Cell Res 9:135-175

Van Oppen MJ, Koolmes EM, Veron JEN (2004) Patterns of evolution in the scleractinian coral genus Montipora (Acroporidae). Mar Biol 144:9-18

van Oppen MJ, McDonald BJ, Willis B, Miller DJ (2001a) The evolutionary history of the coral genus Acropora (Scleractinia, Cnidaria) based on a mitochondrial and a nuclear marker: reticulation, incomplete lineage sorting, or morphological convergence? Mol Biol Evol 18:1315-1329

van Oppen MJ, Palstra FP, Piquet AM, Miller DJ (2001b) Patterns of coral-dinoflagellate associations in Acropora: significance of local availability and physiology of Symbiodinium strains and host- symbiont selectivity. Proc R Soc Lond B 268:1759-1767

Van Oppen MJ, Willis BL, Vugt HW, Miller DJ (2000) Examination of species boundaries in the Acropora cervicornis group (Scleractinia, cnidaria) using nuclear DNA sequence analyses. Mol Ecol 9:1363-1373

Viard F, Franck P, Dubois M-P, Estoup A, Jarne P (1998) Variation of microsatellite size homoplasy across electromorphs, loci and populations in three invertebrates species. J Mol Evol 47:42-51

Vollmer SV, Palumbi SR (2002) Hybridization and the evolution of reef coral diversity. Science 296: 2023-2025

Weir B, Cockerham C (1984) Estimating F-statistics for the analysis of population structure. Evolution 38:1358-1370

Weis VM, Reynolds WS, deBoer MD, Krupp DA (2001) Hostsymbiont specificity during onset of the symbiosis between the dinoflagellates Symbiodinium spp. and planula larvae of the scleractinian coral Fungia scutaria. Coral Reefs 20:301-308 